Model Pembiayaan Pra Panen Pada Rantai Pasok Agribisnis Berdasarkan Sistem Produksi Komoditas Cabai Merah Dengan

Orientasi Pasar Terstruktur (Eddy Renaldi, Tuti Karyani, Agriani Hermita Sadeli, dan Hesty Nurul Utami)

\title{
MODEL PEMBIAYAAN PRA PANEN PADA RANTAI PASOK AGRIBISNIS BERDASARKAN SISTEM PRODUKSI KOMODITAS CABAI MERAH DENGAN ORIENTASI PASAR TERSTRUKTUR
}

\author{
Eddy Renaldi, Tuti Karyani, Agriani Hermita Sadeli, dan Hesty Nurul Utami \\ Fakultas Pertanian, Universitas Padjadjaran \\ E-mail: eddyrenaldi90@gmail.com
}

\begin{abstract}
ABSTRAK. Fluktuasi harga cabai merah yang cukup tinggi saat ini ini disebabkan oleh pasokan cabai merah dari sentra produksi ke pasar yang tidak berkesinambungan dan tidak terstruktur sebagai akibat petani yang tidak mengembangkan basis produksi. Salah satu komponen pengembangan basis produksi cabai merah di Indonesia adalah komponen keuangan yang dapat dilakukan melalui Supply Chain Financing dimana resiko dan pengembalian dari penyedia keuangan ditanggung bersama oleh pelaku dalam rantai pasok. Komponen keuangan berupa modal usaha di sistem produksi menjadi salah satu kendala pengembangan agribsnis cabai merah, karena sulitnya memperoleh bantuan pembiayaan akibat karakteristik usaha agribisnis dan risiko yang ditimbulkannya. Model pembiayaan pra panen pada rantai pasok agribisnis akan memperkuat pengembangan basis produksi yang selanjutnya dapat diperluas menjadi klaster agribisnis cabai merah di Jawa Barat, bahkan dapat direplikasi pada tingkat nasional. Melalui pembiayaan rantai pasok diharapkan dapat meningkatkan pengembalian atas investasi dan pertumbuhan dan daya saing rantai pasok itu. Riset aksi ini dilakukan melalui metode studi kasus melalui identifikasi Value Stream Mapping dan pendekatan pemodelan kualitatif yang dilakukan di salah satu sentra produksi cabai merah di Jawa Barat, yakni Kabupaten Garut, Desa Cigedug. Untuk menghasilkan cabai dengan kualitas yang baik dan kontinyu harus didukung dengan ketersediaan sarana produksi yang sesuai dengan kebutuhan petani benih cabai dan petani cabai yang diberikan pada tingkat kelompok tani atau koperasi yang memasarkan cabai ke pasar terstruktur. Pembeli dari pasar terstruktur melalui kontrak yang memuat jumlah, kualitas dan harga cabai yang disepakati dapat menjamin kesetabilan pendapatan petani. Dalam hal ini pembeli menjadi penjamin dalam kelancaran pembayaran dari pembiayan yang diberikan kepada petani.
\end{abstract}

Kata-kata kunci: pembiayaan, rantai pasok, cabai merah, pasar terstruktur

\section{FUNDING MODEL OF PRE-HARVEST SUPPLY CHAIN BASED PRODUCTION SYSTEMS AGRIBISNIS RED CHILI WITH COMMODITY MARKET ORIENTATION STRUCTURED}

\begin{abstract}
A high fluctuation on red chili price today is occurring due to the unsustainable supply of red chili from the production centers and the unstructured production to the markets. It is cause by farmers farming system, which not develop a production base technique. Financial factor is one of determinant component to develop red chili production base in Indonesia, which can be supported through Pre-harvest financing model for agribusiness supply chain. It is a model where risks and returns of financial providers is shared among the supply chain actors. Financial components in form of working capital for production systems are one of the main constraints for red chili agribusiness development in Indonesia. Farmers stiffness to obtain financing assistance is caused by the characteristics and the risks of red chili agribusiness. Furthermore, the proposed of this financing model will strengthen the development of production base, which can be expanded for red chili agribusiness cluster in West Java or even to be replicated for national level. Financing assistance along the supply chain is expected to improve return on investment, growth and competitiveness. Action research was conducted through a case study by identification of the Value Stream Mapping and qualitative modeling approach was took at one of red chili production center in West Java, namely Garut regency in Cigedug village. A continuous and high quality of red chili production is importantly needed for structured market with definite demand such as food industry, modern retail, or even export market can to be supported by the availability of production according to the needs of growers and nursery farmers which inform by farmer groups or co-operative as the seller for farmers commodity to the market. Buyers from structured market will give a contract agreement, which cover the supply of commodity quantity, quality specification and price and it can guarantee farmers' income stability. Buyer will become the guarantor for the farmer payment continuity to the financing provider.
\end{abstract}

Key words: finance, supply chain, red chili, structured market 


\section{PENDAHULUAN}

Cabai merupakan salah satu komoditas sayuran yang memiliki fluktuasi harga yang tinggi. Fluktuasi harga tersebut berpengaruh pada tingkat inflasi harga komoditas pangan yang dipantau pemerintah Indonesia setiap tahunnya (Badan Pusat Statistika, 2012). Dalam kondisi tertentu harga cabai merah di Indonesia bisa mencapai Rp. 100.000,- per $\mathrm{kg}$ dan pada kondisi tertentu lainnya dapat mencapai harga sebesar Rp. 4.000,- per kg.

Fluktuasi harga tersebut disebabkan oleh pasokan cabai merah dari sentra produksi ke pasar yang tidak berkesinambungan. Data Badan Pusat Statistika dan Direktorat Jenderal Hortikultura (2012) menunjukkan bahwa selama kurun waktu 2007-2011 terjadi surplus produksi cabai merah di Indonesia, artinya konsumsi cabai merah nasional masih di bawah jumlah produksi cabai merah nasional. Namun demikian, karena produksi cabai merah di sentra produksi tidak berkesinambungan maka ketersediaan cabai merah di pasar konsumsi berfluktuasi, demikian juga dengan harganya.

Ketidaksinambungan produksi tersebut disebabkan oleh petani yang tidak melakukan jadwal tanam dalam budidaya cabai merah . Hal tersebut terjadi karena keputusan produksi petani ditentukan oleh penguasaan lahan, kondisi iklim serta pemilihan pasar tradisional sebagai target pasar. Pasar tradisional tidak menuntut petani menjual hasil produksinya secara berkesinambungan berdasarkan spesifikasi kualitas tertentu. Kondisi tersebut berbeda dengan karakteristik pasar terstruktur (industri pengolahan, eksportir, pasar ritel modern dan jasa pangan) yang menuntut produsen atau pelaku lain di sentra produksi untuk dapat memasok hasil produksinya secara berkesinambungan berdasarkan spesifikasi produk dan harga yang ditentukan (Tomy Perdana et al, 2011).

Fluktuasi harga cabai merah menyebabkan ketidakpuasan konsumen sehingga mengalihkan pembelian pada produk subtitusi yang berasal dari impor. Bagi produsen, fluktuasi harga tersebut menyebabkan risiko usaha yang tinggi. Dalam jangka panjang kondisi tersebut menyebabkan berkurangnya minat petani dan investor untuk melakukan budidaya cabai merah sehingga ketersediaan cabai merah lokal akan digantikan oleh produk impor.

Salah satu komponen pengembangan klaster agribisnis cabai merah di Indoensia adalah komponen keuangan (Perdana, Nurhayati and Kusnandar, 2013). Komponen atau aliran uang merupakan salah satu dari empat aliran dalam manajemen rantai pasok pertanian. Aliran uang akan menentukan kelancaran dan kesinambungan dalam aliran produk (Perdana dan Avianto, 2008). Pengembangan keuangan dalam rantai pasok dan klaster agribisnis harus dilakukan secara holistik. Artinya, pengembangannya tidak dapat dilakukan secara terpisah seperti skema keuangan atau pembiayaan pertanian yang ada saat ini. Oleh karena itu, perlu dikembangkan suatu model pembiayaan rantai pasok pertanian (agricultural supply chain finance) pada komoditas cabai merah, khususnya yang berorientasi pasar terstruktur.

Menurut Robinson dalam Hoffman (2011) Supply Chain Financing adalah bagaimana mengelola modal kerja, arus kas antara perusahaan sepanjang rantai pasokan baik dalam bentuk pembayaran antara vendor dan pembeli atau dalam bentuk keuangan. Melalui pembiayaan rantai pasok, resiko dan pengembalian dari penyedia keuangan ditanggung bersama oleh pelaku dalam rantai pasok.

Kolaborasi antar pelaku pada Supply Chain Financing dicerminkan dengan komitmen dalam berbagi sumber daya, kapabilitas, informasi dan resiko berdasarkan kontrak jangka mengeah atau jangka panjang. Pembaiayaan rantai pasok Kontribusi instrumental pembiayaan rantai pasok didasarkan pada tiga unsur konstitutif: (1) pelaku kelembagaan, (2) karakteristik manajemen rantai pasokan, dan (3) fungsi keuangan. Unsur-unsur ini, merupakan kerangka pembiayaan rantai pasok yang kana menjadi bahan pertimbangan dalam membuat keputusan mengenai keuangan dalam rantai nilai (Hofmann, 2005).

Model pembiayaan rantai pasok pertanian tersebut akan memperkuat pengembangan klaster agribisnis cabai merah di Jawa Barat, bahkan dapat direplikasi pada tingkat nasional. 
Pembiayaan rantai pasok adalah produk keuangan dan jasa yang mengalir ke atau melalui setiap titik dalam rantai pasok dalam rangka meningkatkan pengembalian atas investasi dan pertumbuhan dan daya saing rantai pasok itu. Dengan pembiayaan rantai pasok, resiko dan pengembalian dari penyedia keuangan ditanggung bersama oleh pelaku dalam rantai pasok (USAID, 2010).

Kunci keberhasilan pembiayaan adalah dengan melibatkan pihak bank agar dapat memahami kebutuhan petani, mengetahui kekuatan dan kelemahaan cashflow serta kesulitan dalam penyediaan jaminan (Anonim, 2012). Oleh karena itu diperlukan penelitian yang mengkaji mengenai pembiayaan pra panen agar pihak pemberi pembiayaan yaitu bank maupun pihak lainnya dapat memahami petani dalam melakukan analisa kredit serta mengetahui skema pembiayaan yang tepat untuk diberikan kepada petani cabai merah.

\section{METODE}

Penelitian ini merupakan riset aksi (action research) yang menggunakan metode studi kasus. Penelitian ini akan dilakukan di salah satu sentra produksi utama cabai merah di Jawa Barat, yakni Kabupaten Garut, Desa Cigedug. Dalam melakukan identifikasi kebutuhan pembiayaan rantai pasok akan digunakan Value Stream Mapping yang dilakukan sejalan dengan observasi dan wawancara pada rantai pasok cabai merah yang berorientasi pasar terstruktur. Sedangkan untuk memodelkan pembiayaan rantai pasok cabai merah akan digunakan pendekatan pemodelan kualitatif (qualitative modeling).

\section{HASIL DAN PEMBAHASAN}

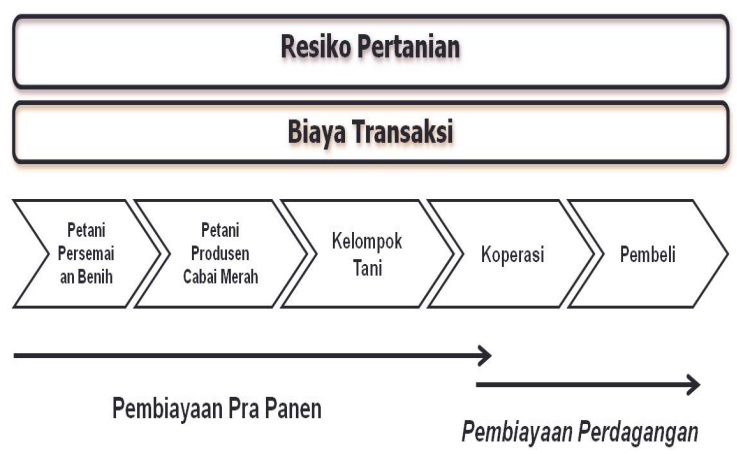

Gambar 1. Proses Bisnis Budidaya Cabai Merah di Desa Cigedug Kabupaten Garut
Masing-masing pelaku memiliki peran di dalam rantai pasok cabai merah. Pelaku dalam rantai pasok adalah petani persemaian benih, petani cabai merah, kelompok tani, koperasi dan pembeli.

Petani persemaian benih, pelaku ini berada di sub sistem budidaya pertanian dan berperan untuk menyediakan benih cabai merah yang akan dijual kepada petani cabai merah. Untuk menghasilkan benih yang berkualitas baik, maka petani persemaian benih membutuhkan sarana produksi benih dengan kualitas dan kuantitas yang sesuai dan tepat dengan kebutuhan petani. Sehingga pelaku penangkar benih membutuhkan modal serta pembiayaan untuk menjalankan usahanya sesuai dengan karakteristik kebutuhan bisnisnya. Waktu yang dibutuhkan petani persemai benih untuk menghasilkan benih cabai dapat mencapai 28 hari.

Petani cabai merah, pelaku ini juga berada pada sub sistem budidaya pertanian yang berperan sebagai produsen cabai merah. Dalam melakukan usahanya, petani membutuhkan informasi baik mengenai saprodi maupun informasi pasar mengenai spesifikasi komoditas cabai merah yang dibutuhkan oleh konsumen, baik hasil panen petani tersebut akan dipasarkan ke pasar tradisional maupun ke pasar terstruktur yang sudah berdasarkan kontrak. Dengan demikian, untuk mendapatkan hasil panen cabai merah yang berkualitas, maka petani sebagai produsen harus mampu mendapatkan pasokan benih yang berkualitas dari petani persemai benih dan saprodi lainnya yang mendukung hasil budidaya yang baik dari segi kualitas maupun kuantitas. Namun demikian, skala usaha budidaya cabai merah di tingkat petani masih banyak yang berskala kecil, sehingga kebutuhan saprodi juga dibutuhkan dalam jumlah yang relatif kecil. Dalam menjalankan usahataninya, petani tetap membutuhkan pembiayaan untuk kelancaran serta keberlanjutan usaha produksinya karena usaha agribisnis bersifat musiman yang akan berdampak pada fluktuasi pendapatan petani. Waktu yang dibutuhkan untuk budidaya tanaman cabai dari masa tanam sampai panen pertamandapat mencapai 120 hari karena 
Garut merupakan lokasi yang berada pada dataran tinggi. Sedangkan masa panen dapat berlangsung selama 42 hari.

Kelompok tani/gabungan kelompok tani, sebagai tempat menyalurkan informasi dan diskusi mengenai kualitas, kuantitas, dan kontinuitas dari hasil panen cabai merah yang disesuaikan dengan kontrak, serta penyalur sarana produksi secara kolektif serta membantu mendistribusikan hasil panen cabai merah dari petani ke koperasi. Namun demikian, kelompok tani tidak selalu berjalan sesuai dengan fungsinya dan terkadang pada kasus di beberapa wilayah penelitan menunjukkan bahwa banyak kelompok tani yang sudah tidak berfungsi dan hanya digunakan sebagai sarana formalitas untuk mendapatkan bantuan pemerintah.

Koperasi, sebagai penyalur hasil panen cabai yang dipasok dari kelompok tani maupun petani secara langsung. Pembayaran dari hasil panen cabai yang telah dikirim ke pembeli, akan dibayar melalui koperasi, lalu koperasi akan menyalurkannya ke kelompok tani atau petani. Selain itu koperasi berperan sebagai penyedia saprodi yang diperlukan untuk budidaya cabai merah petani anggota. Selain itu, koperasi membuat jadwal tanam per kelompok tani sehingga waktu dan jumlah panen sudah dapat diprediksi agar proses produksi bisa kontinyu.

Pembeli, sebagai pembeli hasil panen petani melalui koperasi berdasarkan kontrak yang sudah disepakati mengenai kuantitas, kualitas, kontinuitas, harga, serta sistem pembayaran. Pembeli menentukan cara budidaya yang tepat agar cabai dengan kualitas yang diinginkan. Pembayaran dilakukan setelah cabai merah diterima dan dinyatakan masuk dalam kualifikasi yang diinginkan.

Persyaratan kontrak terkait dengan kuantitas, kualitas, dan kontinuitas di level produksi, maka kelompok tani harus memahami dan mengaplikasikan sistem produksi yang berkembang menjadi basis produksi yang menerapkan mengenai pola tanam, jadwal tanam, dan jadwal panen sehingga dapat diketahui dengan pasti kebutuhan sarana produksi yang dibutuhkan sesuai dengan jadwal tanam. Dengan demikian, kebutuhan pasar akan terpenuhi tepat waktu, tepat jumlah, tepat varietas, dan tepat kualitas. Pemenuhan sarana produksi harus didukung dengan keuangan yang memadai. Salah satu langkah yang dapat ditempuh adalah melalui pembiayaan pra panen.

\section{Model Pembiayaan Pra Panen}

Pembiayaan Prapanen dapat diaplikasikan dengan memberikan pem-biayaan kepada koperasi dan kelompok tani yang sudah terikat kontrak atau perjanjian kerjasama baik secara langsung maupun tidak langsung dengan eksportir dan pembeli dari pasar modern. Pembeli bertindak sebagai penjamin atau avalis dimana pembeli memberikan jaminan pasar melalui kontrak sehingga meningkatkan kemampuan petani dalam melakukan kewajiban pembayaran angsuran. Cara pembayaran angsuran didukung dengan peran koperasi yang merupakan wadah berlangsungnya pengelolaan keuangan yang berasal dari

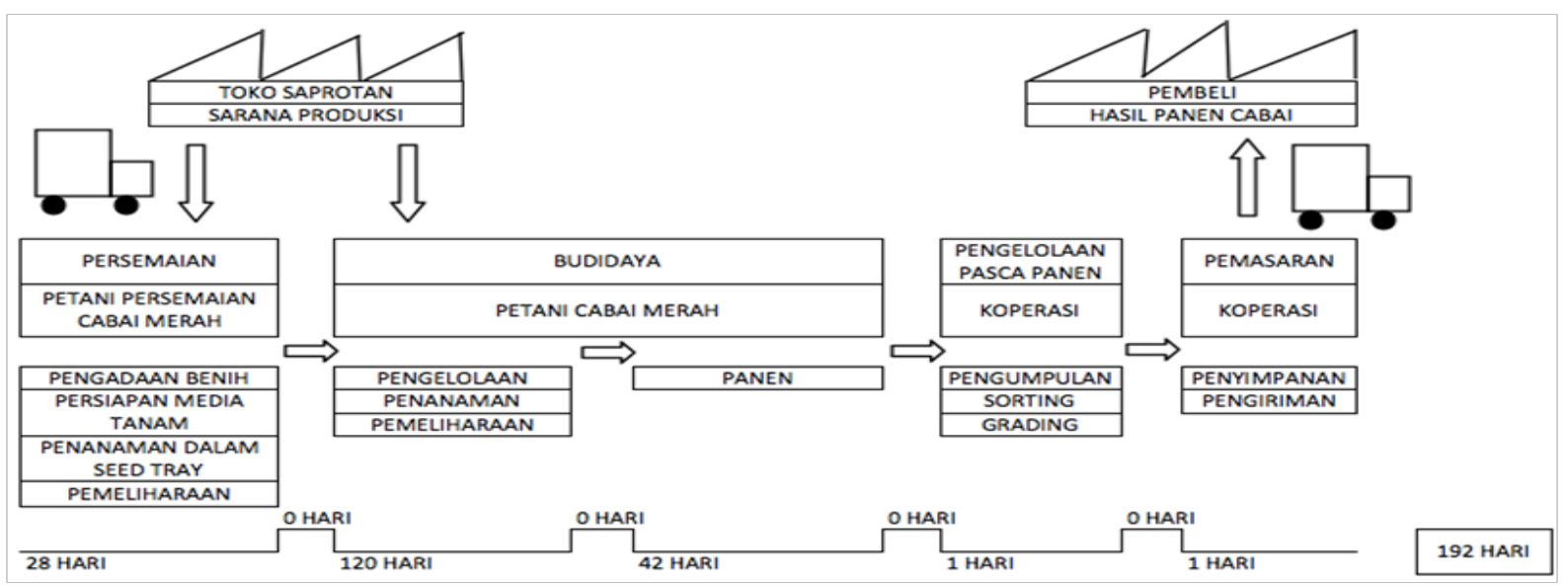

Gambar 2. Value Stream Mapping Rantai Pasok Cabai Merah 
pembayaran hasil panen cabai. Sehingga resiko terjadinya tunggakan dapat ditekan.

Koperasi berperan sebagai pengelola keuangan serta pengadaan sarana produksi petani. Dengan adanya kelompok tani akan menghasilkan aliran uang serta aliran barang menjadi lebih terorganisir serta efisien dan efektif. Mengingat kebutuhan petani sarana produksi yang relatif dalam jumlah sedikit sehingga akan lebih efisien jika dilakukan pengadaan secara kolektif oleh kelompok tani melalui koperasi. Oleh karena itu perlu untuk dibentuk kelompok tani baik kelompok tani cabai merah maupun kelompok tani persemaian cabai merah yang tergabung dalam koperasi.

Keterangan :

1.Petani Produsen memberikan informasi mengenai kebutuhan sarana produksi kepada kelompok tani

2.Kelompok Tani memberikan informasi mengenai kebutuhan sarana produksi kelompok tani kepada koperasi

3.Koperasi mengajukan kebutuhan sarana produksi kepada toko saprotan yang sudah memiliki kontrak kerja sama dengan koperasi

4. Toko Saprotan mengirim sarana produksi sesuai dengan pengajuan yang diajukan koperasi Koperasi mengirimkan sarana produksi sesuai dengan pengajuan yang diajukan kelompok tani

5.Kelompok tani mengirimkan sarana produksi sesuai dengan pengajuan petani produsen

6. Koperasi meminta pihak bank untuk membiayai pembelian saprotan ke pihak bank

7.mendanai pembelian saprotan sesuai dengan pengajuan koperasi kepada toko saprotan

8. Petani produsen menghasilkan panen cabai langsung dikirim ke koperasi secara langsung tanpa melewati kelompok tani

9. Koperasi mengirimkan hasil cabai merah yang sudah dilakukan perlakuan pasca panen

10. Pembeli membayar sejumlah uang sesuai dengan jumlah cabai merah setelah dilakukan

sortasi oleh pihak pembeli

11.Bank membayarkan sejumlah uang ke koperasi setelah pihak bank melakukan autodebit untuk pembayaran pembiayaan saprodi

12.Koperasi mendistribusikan uang hasil pembayaran panen kepada petani produsen

14.Pendampingan kepada kelompok tani dilakukan oleh penyuluh

15. Pendampingan kepada petani dilakukan oleh penyuluh

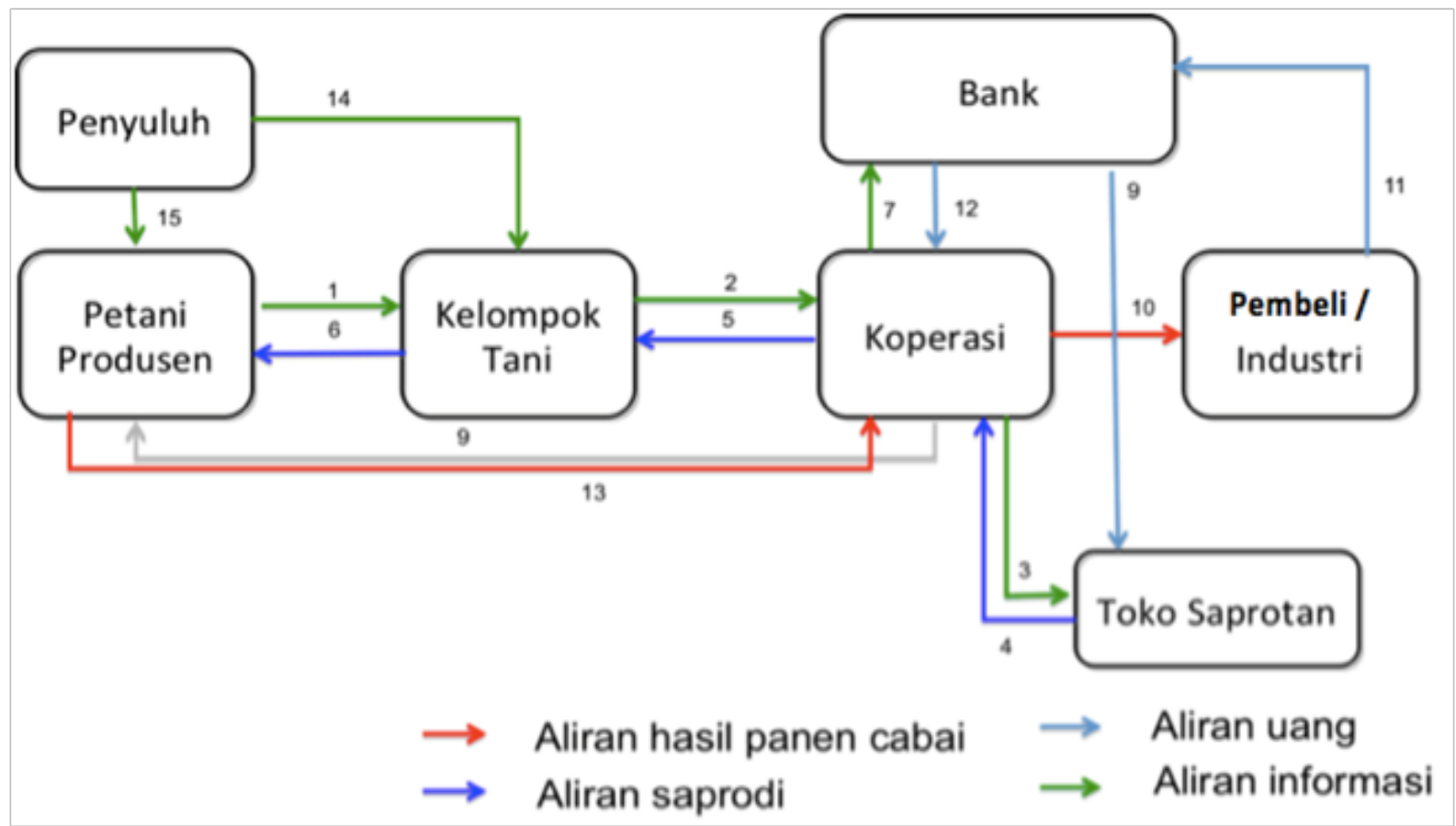

Gambar 3. Model Pembiayan Rantai Pasok Pra Panen Cabai Merah 


\section{Simulasi Pembiayaan untuk Petani}

Untuk lebih memperkuat bahwa usahatani cabai merah prospeknya sangat baik maka dikakukan simulasi dengan menggunakan sensitivitas meningkatkan harga, menurunkan biaya produksi. Asumsi yang digunakan sebagai berikut:

Tabel 2. Asumsi Pembiayaan untuk Petani

\begin{tabular}{lc}
\hline a. Jumlah tanaman cabai per Hektar & 15.000 pohon \\
\hline b. Taksasi produksi perpohon $0,5 \mathrm{~kg}$ & $12.750 \mathrm{Kg}$ \\
c. Harga kontrak pembeli dengan pembeli perkg & $\mathrm{Rp} .10 .000$ \\
Bagian Untuk petani $70 \%$ & Rp. 7.000 \\
Bagian untuk koperasi $30 \%$ & Rp. 3.000 \\
\hline
\end{tabular}

Berdasarkan analisis sebelumnya, maka dibuat simulasi tingkat penerimaan, pengeluaran dan keuntungan usahatani cabai merah pada Tabel 3. Berdasarkan hasil perhitungan simulasi secara individual maka usahatani cabai merah menguntungkan (RC $>1$ ), dengan asumsi tidak ada risiko yang harus ditanggung. Namun demikian untuk melakukan usahatani cabai memerlukan dana operasional yang cukup besar yaitu sekitar Rp. 60.000.000,00. Adapun pembiayaan atau kredit yang diberikan tentunya tidak semua dari dana luar melainkan sekitar 50\% sampai $60 \%$ yang bisa didanai. Misalnya bila jumlah kredit yang diberikan bank sebesar Rp. 30.000.000 per Ha, dengan tingkat bunga $17 \%$ (untuk UMKM) serta dibebani asuransi 2,5\% per tahun, maka secara kumulatif per hitungan angsuran dan beban yang harus dibayar petani dapat dilihat pada Tabel 4 .

Namun demikian, untuk lebih rincinya analisis ini dengan mempertimbangkan kondisi eksisting yaitu disesuaikan dengan volume cabai yang dikirim per minggu, rata-rata estimasi dari pembeli (industri pengolahan) untuk satu musim tanam kemampuan panen mencapai 14 kali. Dengan asumsi dalam satu hektar terdapat 15.000 pohon dengan prediksi bahwa susut dengan berbagai sebab sebesar $20 \%$ di kebun, dan penyusutan di koperasi saat penanganan pasca panen yang diperkirakan 19\% maka jumlah produksi per minggu rata-rata mencapai $4.860 \mathrm{~kg}$. Namun kenyataannya dari 14 kali panen besarnya produksi tidak merata, panen pertama sampai ke lima masih sedikit tetapi meningkat dan mencapai puncaknya pada panen ke 9 atau umur cabe sekitar $6-7$ bulan. Selanjutnya dari panen ke 10 sampai ke 14 menurun lagi.

Tabel 3 Simulasi Penerimaan, Keuntungan, RC ratio dan $\mathrm{BC}$ ratio Usahatani Cabai merah per Hektar

\begin{tabular}{|c|c|c|}
\hline Kondisi Normal & Harga & Jumlah \\
\hline Penerimaan & 70.000 & Rp. 89.250 .000 \\
\hline Biaya produksi & & Rp. 59.775.000 \\
\hline Keuntungan & & Rp. 29.475 .000 \\
\hline $\mathrm{R} / \mathrm{C}$ & & 1,49 \\
\hline $\mathrm{B} / \mathrm{C}$ & & 0.49 \\
\hline \multicolumn{3}{|c|}{$\begin{array}{l}\text { Harga meningkat melebihi Rp. } 14.000 / \mathrm{kg} \text {, (harga kontrak } \\
\text { awal+harga pasar) } / 2 \text {, misal Rp. } 20.000 / \mathrm{kg} \text {, maka harga petan } \\
70 \% \text { X } 15000=\text { Rp. } 10.500\end{array}$} \\
\hline Penerimaan & 10.500 & \\
\hline $12.750 \mathrm{~kg}$ & & 133.875 .000 \\
\hline Biaya Produksi & & Rp. 59.755.000 \\
\hline Keuntungan & & Rp. 74.100 .000 \\
\hline $\mathrm{R} / \mathrm{C}$ & & 2,24 \\
\hline $\mathrm{B} / \mathrm{C}$ & & 1,24 \\
\hline \multicolumn{3}{|c|}{ Biaya naik $10 \%$, harga kontrak tetap } \\
\hline Penerimaan & 7000 & \\
\hline $12.750 \mathrm{~kg}$ & & Rp. 89,250,000 \\
\hline Biaya Produksi & & Rp. 61,880,500 \\
\hline Keuntungan & & Rp. 27,369,500 \\
\hline $\mathrm{R} / \mathrm{C}$ & & 1.44 \\
\hline $\mathrm{B} / \mathrm{C}$ & & 0.44 \\
\hline
\end{tabular}

Tabel 4. Analisis Angsuran Pinjaman yang harus dibayar Petani per Hektar

\begin{tabular}{ll}
\hline Keterangan & Jumlah (Rp) \\
\hline Kredit & 30.000 .000 \\
Premi asuransi 2,5\% & 750.000 \\
Total Kredit & 30.750 .000 \\
Total Biaya Kredit (17\%) & 5.227 .500 \\
Biaya kredit per bulan (flat) & 435.625 \\
Angsuran pokok & 2.562 .500 \\
Angsuran pokok + biaya & 2.998 .125 \\
Angsuran pokok+biaya/minggu & 749.531 \\
\hline
\end{tabular}

\section{Simulasi Pembiayaan untuk Koperasi}

Industri pengolahan sebagai pembeli menggunakan sistem pembayaran dengan sistem tunda bayar selama satu bulan, maka 
koperasi mengajukan pembiayaan ke bank sesuai kebutuhan untuk menutup pembayaran dan biaya penanganan pasca panen. Analisis cash flow di koperasi dengan memperhatikan kebutuhan koperasi untuk mengoperasikan kegiatannya maka dengan asumsi luas tanam satu hektar, maka kebutuhan dana pinjaman Rp. 30.000.000. Dari proyeksi produksi yang dibuat oleh Industri pengolahan yang diasumsikan panen cabai merah dapat dipanen sebanyak 14 kali.

Sebagaimana dijelaskan sebelumnya bila koperasi mengajukan pembiayaan dan diasumsikan yang dibiayai hanya yang berkaitan dengan biaya penanganan hasil cabai merah per minggu. Hasil analisis menunjukkan keuntungan mencapai Rp 1,715,901 per ha/minggu. Namun bila biaya manajemen juga dibebankan pada usaha melalui pasar terstruktur, maka analisisnya juga memperlihatkan hasil masih menguntungkan yaitu mencapai $\mathrm{Rp}$. 174,181 per ha/minggu .

\section{SIMPULAN}

Kelompok tani harus memahami dan mengaplikasikan keinginan konsumen yang akan dijadikan basis produksi dengan menerapkan mengenai pola tanam, jadwal tanam, dan jadwal panen sehingga dapat diketahui dengan pasti kebutuhan sarana produksi yang dibutuhkan.

Pembiayan pra panen dapat diaplikasikan dengan memberikan pembiayaan kepada kelompok tani yang sudah terikat kontrak atau perjanjian kerjasama

Persyaratan untuk memanfaatkan pembiayaan rantai pasok pra panen yaitu adanya kelompok tani, koperasi sebagai pengatur aliran uang dan barang, pembeli sebagai penjamin atau avalis

Koperasi berperan sebagai pengelola keuangan serta pengadaan sarana produksi petani.

\section{REKOMENDASI}

Adanya pendampingan mengenai basis produksi, pemahaman yang sama dan kuat mengenai rantai pasok hortikultura

Pada tahap awal harus ada proses pendampingan dan manajemen koperasi harus sudah terkelola dengan baik (manajemen yang profesional)
Bank mendapatkan pendampingan mengenai model pembiayaan yang khusus untuk agribisnis cabai merah

Akses pembiayaan harus disesuaikan dengan cash flow dan kebutuhan masing masing pelaku dalam rantai pasok

\section{UCAPAN TERIMA KASIH}

Ucapan terima kasih kami sampaikan kepada LPPM Universitas Padjadjaran yang telah membiayai penelitian ini melalui skema KILAB serta kepada semua pemangku kepentingan yang telah turut berpartisipasi memberikan dukungan data dan informasi dalam penyelesaian penelitian ini.

\section{DAFTAR PUSTAKA}

Anonim. 2012. Innovative Agricultural SME Finance models. International Finance corporation 2012. Washington.

Checkland P., 2000. Soft Systems Methodology : A Thirty Year Retrospective, System Research and Behavioral Science 17 (2000) S11-S58

Coyle G., 2000. Qualitative and Quantitative Modelling in System Dynamics : Some Research Questions, System Dynamics Review Vol 16 No 3 (2000) 225-244.

Hofmann, Erik. 2005. Supply Chain Finance: some conceptual insights. KühneInstitut für Logistik (KLOG-HSG) Universität St.Gallen Dufourstrasse. Wiesbaden.

Hofmann, Erik \& Belin, Oliver. 2011. Supply Chain Finance Solutions Relevance-Propositions-Market Value. Springer-Verlag: Berlin.

KIT and IRR. 2010. Value Chain Finance: Beyond Microfiance for Rural Entrepreneurs. Royal Tropical Institute, Amsterdam; and International Institute of Rural Reconstruction, Nairobi.

Karyani, Tuti dkk. 2011. Lembaga Keuangan Perdesaan: Permasalahan dan Solusinya. Bandung: Unpad Press. 
Miller, Calvin. 2011. Agricultural Value Chain Finance Strategy and Design. Food and Agriculture Organization

Perdana T, Noor TI, Wulandari E, Purnomo D, Kusnandar., 2011. System Dynamics Modelling for Indonesian Small Farmers Exported Fruits and Vegetables Supply Chain Management. This article was being presented in "Workshop on System Modelling for Policy Development: Rehearsing Iniatives" October $22^{\text {nd }}$ 2011 in Hotel Le Meredien Jakarta, a collaboration between President's Delivery Unit for Development Monitoring and Oversight (UKPPPP) and School of Business and Management, Bandung Institute of Technology.

Perdana T, Kusnandar., 2012. The Triple Helix Model for Fruits and Vegetables Supply Chain
Management Development Involving Small Farmers in Order to Fulfill the Global Market Demand: a Case Study in "Value Chain Center (VCC) Universitas Padjadjaran”. Procedia - Social and Behavioral Sciences 52 (2012) 80-89.

Rodriguez-Ulloa RA, Montburn A, Martinez-Vicente S., 2011. Soft System Dynamics Methodology in Action : A Study of the Probele of Citizen Insecurity in an Argentinean Province, Systemic Practice and Action Research 24 (2011) 275-323

Statistics Indonesia and Directorate General of Horticulture., 2013. Horticulture Statistics. at http://deptan.go.id Accesed on June.

Statictics West Java., 2013. Horticulture Statistics. at http://diperta.jabarprov. go.id. Accesed on June. 